Original Article

\title{
Elevated Level of Plasma B-Type Natriuretic Peptide (BNP) as a Prognostic Marker in Patients with Acute Coronary Syndrome. \\ *Parvin $D^{1}$, Uddin $M N^{2}$, Kabir MS $S^{3}$, Ahmed $A^{4}$, Hossain $M S R^{5}$, Rahman MM', Hoque MMP
}

\begin{abstract}
Acute coronary syndrome (ACS), a life-threatening manifestation of coronary artery disease, ranges from unstable angina (UA) to acute myocardial infarction (AMI). To reduce the morbidity and mortality resulting from acute coronary syndrome, we should have to find out some predictor or prognostic indicator. A prognostic indicator should be available at the time of initial patient's evaluation, in order to maximize the potential benefits of early risk assessment. This study designed to evaluate plasma BNP as a prognostic tool in patients with acute coronary syndrome. A prognostic cohort study was carried out with 90 (ninety) acute coronary syndrome patients on the basis of their clinical and laboratory criteria with age range of 30 to 90 years in the department of biochemistry, BSMMU, in collaboration with department of cardiology, NICVD, $B S M M U$ and BIRDEM. Plasma BNP concentrations were measured on enrollment and then grouping of the study subjects were done on the basis of their empirical cut off value of plasma BNP concentration. All the patients were free from heart failure, renal disease, thyroid disease and hepatic disorder. Main outcomes were mortality, morbidity and survival after hospital discharge with or without any disability. All the subjects were categorized into two and to see the significance between two groups in relation to age and sex Unpaired - $t$ test and Chi square test were done. Finally, Binary logistic regression was done. Among 90 acute coronary syndromes
\end{abstract}

1. *Dr. Dilshad Parvin, Assistant Professor, Department of Clinical Biochemistry, NICVD, Dhaka

E-mail: drsdilshad72@gmail.com

2. Dr. Md Nasir Uddin, Associate Professor, Department of Biochemistry, NICVD, Dhaka

3. Md. Shahjahn Kabir, Consultant,Department of Cardiology, BIRDEM General Hospital, Dhaka

4. Dr. Afsana Ahmed, Department of Biochemistry, Dhaka National Medical College, Dhaka

5. Dr. S M. Rahat Hossain, Assistant Professor, Dept. of Microbiology, Sheikh Hasina Medical College, Tangail.

6. Dr. Md Mahbubur Rahman, Associate Professor, Department of Cardiology, NICVD,

7. Prof. Dr. Md. Mozammel Hoque, Professor and Chairman, Department of Biochemistry, Bangabandhu Sheikh Mujib Medical University ( BSMMU), Dhaka

*For Correspondence patients, there were $74(82.2 \%)$ male and 16(17.8\%) female with mean age of the study population 51.8 years and the age range of 30 to 90 years. Among enrolled patients, 24 (26.7\%) were NSTEMI and 66 (73.3\%) were STEMI that includes 29 (32.2\%) anterior MI, 21 (23.3\%) inferior MI, 16 (17.8\%) other varieties of MI. All the study subjects were grouped into two on the basis of empirical cut off value of plasma BNP $640 \mathrm{pg} / \mathrm{ml}$ on enrollment. Group I with plasma BNP level less than 640pg/ml includes 57 (63.3\%) subjects and group II with plasma BNP more than 640pg/ml includes 33 (36.7\%) subjects. Among group I $(n=57)$ good recovery, morbidity and mortality found to be in 41(71.9\%), 15(26.3\%) and 1(1.8\%) patients and those in group II $(n=33)$ found in $6(18.2 \%)$, $19(57.6 \%)$ and $8(24.2 \%)$ patients respectively. Keeping the group I in reference category binary logistic regression analysis done, showing odds ratio 11.5 with p-value 0.000. The odds ratio 11.5 indicates that there is 11.5 times higher chance of getting bad outcome in ACS patients having higher plasma BNP concentrations.

Key words: BNP, Acute Coronary Syndrome.

\section{INTRODUCTION}

Coronary heart disease is the leading cause of mortality \& morbidity worldwide affecting millions of peoples in both developed \& developing countries. ${ }^{1}$ It has been observed that prevalence of CHD is higher in South Asians, with the highest rates among Bangladeshi \& Pakistani origin. ${ }^{2}$ Acute coronary syndrome (ACS) encompass a continuum of cardiac ischemic event ranging from unstable angina with no evidence of biochemical necrosis to non ST elevation myocardial infarction (NSTEMI) and ST elevation myocardial infarction (STEMI). ${ }^{3}$ The usual approach to the treatment of an acute coronary event involves the institution of early aggressive therapeutic strategies aimed at limiting the amount of myocardial injury \& preventing complication. Prioritization of the bare necessity in this context in order to select high risk group for comprehensive therapy which is the only way to reduce the morbidity $\&$ mortality of ACS. ${ }^{4}$ So primary challenge is the early \& specific diagnosis of ACS with identification of high risk group that helps to initiate appropriate therapy without delay. Traditional serum markers of myocardial injury (cardiac enzyme troponin \& myoglobin) in ACS reflect only the sequel of inflammatory milieu \& plaque rupture. In contrast to the injury markers, newly identified serum substances have drawn attention for their ability to portend 
acute coronary events $\&$ their outcomes. New biomarkers, like natriuretic peptide may provide additional pathophysiological insight \& add to the strategy for comprehensive assessment. ${ }^{5}$

B-type natriuretic peptide is a 32 amino acid neurohormone released from ventricular myocardium predominantly in response to increased ventricular wall stores, ventricular

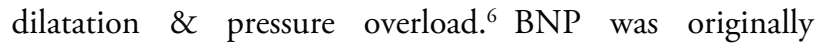
identified in the extract of porcine brain. It is subsequently found that BNP is synthesized in brain but there is considerably more BNP in the cardiac ventricles. The diverse action of BNP includes arterial and venous vasodilatation, natriuresis, diueresis, inhibition of the renninangiotensin-aldosteron system, and inhibition of the sympathetic nerve activity ${ }^{7}$.

BNP have been shown to aid in the diagnosis of heart failure \& to correlate with LV dilatation, remodeling, dysfunction $\&$ the mortality among patient presenting with Acute MI. ${ }^{8}$ After Acute MI, BNP concentration rises rapidly during the first 24 hours and then tends to stabilize. ${ }^{9}$ There is an association between BNP and the short and long term risk of death across the spectrum of ACS including patients without myocardial necrosis or clinical evidence of heart failure. ${ }^{10}$ Plasma BNP concentration measured between one to four days after a transmural infarction provides prognostic information that is independent of the left ventricular ejection fraction and other important baseline variables. ${ }^{11}$ The association between BNP and long term risk of death in ACS is independent of cardiac function, renal function, the troponin I level, electrocardiographic changes and other known risk predictors. ${ }^{12}$

After acute MI, raised concentration of BNP identifies patients at risk for adverse ventricular remodeling, left ventricular dysfunction, heart failure and death independent of age, history of heart failure and left ventricular ejection fraction. Even in patients with unstable angina and no evidence of myocardial necrosis or heart failure, raised concentration of plasma BNP are associated with an increased risk of death. ${ }^{13} \mathrm{BNP}$ is an independent marker for risk stratification in ACS patients. So, elevated level of plasma BNP in ACS patient is serious enough to warrant the follow up examination.

The magnitude of risk relationship of ACS with BNP found to be greater than that with most currently available cardiac markers. Therefore, we want to evaluate the prognostic implications of plasma BNP, a cardiac neurohormone across the entire spectrum of ACS. BNP provides a convenient and noninvasive means to gain insight into the underlying consequences of ACS and thereby may identify high risk target cases for timely specific therapeutic intervention. Since BNP has the potential to improve substantially the outcome in patients with ACS by facilitating its risk assessment and timely clinical decision making process at its very outset, so we have decided to evaluate the prognostic value of plasma BNP in patients with ACS.

\section{MATERIAL \& METHOD}

The present cohort study was conducted in the Dept. of Biochemistry, BSMMU, NICVD \& BIRDEM, Dhaka, Bangladesh during the period from January 2009 to December 2009. A total of 90 diagnosed acute coronary syndrome (ACS) patients free from heart failure, renal disease, thyroid disorder and hepatic disorder were enrolled from the cardiology emergency department of BSMMU, NICVD and BIRDEM. After measurement of plasma BNP concentration, subjects were categorized into two groups. Those having BNP concentration $<640 \mathrm{pg} / \mathrm{ml}$ were included in Group-I and those having plasma BNP concentration $>640 \mathrm{pg} / \mathrm{ml}$ were included in Group II. All patients were treated and managed identically by conventional standard management protocol during their hospital stay and even after their discharge. After discharge all patients were followed up periodically in every month up to 6 months. During hospital stay and their follow up period patients were assessed clinically for any kind of clinical outcomes (good recovery, recurrent ACS, heart failure, cardiogenic shock, stroke, and cardiovascular death.) In every visit patient was evaluated on the basis of clinical assessment, ECG, Echocardiogram, CAG, cardiac markers according to the merit individual case. At the end of follow up patients clinical outcome were evaluated on the perspective of their baseline plasma BNP concentration. All data were recorded systematically in a preformed data collection sheet. Statistical analysis was performed by using Windows SPSS 13.0 version. Unpaired $\mathrm{t}$ - test and Chi-square test was done to see significance between two groups in relation to age and sex. The correlation between two groups with other baseline variables was assessed by Chi square test. To evaluate the association of plasma BNP with clinical outcome, chi-square test and Fissure exact test were done. Finally, Binary logistic regression was done to evaluate prediction of the risk of adverse clinical outcome (end point) based on the baseline plasma BNP concentration.

\section{RESULTS}

In a prognostic cohort study, 90 diagnosed ACS patients were enrolled in the study on the basis of their clinical and laboratory diagnostic criteria. At the outset, plasma BNP concentration of all patients was measured and then followed up. Out of 90 ACS patients 74 (82.2\%) were male and $16(17.8 \%)$ were female with the mean age of 51.8 years and the age range of 30 to 90 years (Table I). 
Table I: Age and sex distribution of study subjects $(\mathbf{n}=90)$ :

\begin{tabular}{|c|c|c|c|}
\hline \multicolumn{2}{|c|}{ Sex } & \multicolumn{2}{c|}{ Age (yrs.) } \\
\hline Male & Female & Mean & Range \\
\hline 74 & 16 & 51.8 & $30-90$ \\
\hline$(82.2 \%)$ & $(17.8 \%)$ & & \\
\hline
\end{tabular}

Among the enrolled patients, 24 (26.7\%) were non-ST-elevation myocardial infarction (NSTEMI) and 66 (73.3\%) were ST-elevation myocardial infarction (STEMI). STEMI includes 29 (32.2\%) anterior MI, 21(23.3\%) inferior MI, and $16(17.8 \%)$ other varieties of MI e.g. anterior-inferior MI, posterior MI, right ventricular MI. (Table II).
Table II: Clinical types of study subjects $(n=90)$ :

\begin{tabular}{|c|c|c|c|}
\hline $\begin{array}{c}\text { NSTEMI } \\
(\mathbf{2 4})\end{array}$ & \multicolumn{3}{|c|}{$\begin{array}{c}\text { STEMI } \\
(\mathbf{6 6})\end{array}$} \\
\hline & Anterior MI & Inferior MI & Others \\
\hline 24 & 29 & 21 & 16 \\
\hline$(26.7 \%)$ & $(32.2 \%)$ & $(23.3 \%)$ & $(17.8 \%)$ \\
\hline
\end{tabular}

Table III shows the comparison of the two groups with respect to the baseline characteristics and clinical types of ACS. With respect to hypertension, diabetes and smoking status two groups found identical but with respect to types of ACS, STEMI found to be more in group II and NSTEMI were more in group I.

Table III: Distribution of baseline characteristics and clinical types of ACS between two groups (n=90):

\begin{tabular}{|c|c|c|c|c|c|c|}
\hline \multirow{2}{*}{ Characteristics } & \multicolumn{2}{|c|}{ Group I (n=57) } & \multicolumn{2}{|c|}{ Group II $(n=33)$} & \multirow{2}{*}{$\begin{array}{c}\mathbf{x}^{2} \\
\text { Value }\end{array}$} & \multirow{2}{*}{$\begin{array}{c}\mathbf{P} \\
\text { Value }\end{array}$} \\
\hline & Frequency & Percentage & Frequency & Percentage & & \\
\hline NSTEMI & 22 & 38.6 & 2 & 6.0 & \multirow{2}{*}{11.314} & \multirow{2}{*}{0.001} \\
\hline STEMI & 35 & 61.4 & 31 & 94.0 & & \\
\hline Hypertensive & 24 & 42.1 & 15 & 45.5 & \multirow{2}{*}{0.095} & \multirow{2}{*}{0.757} \\
\hline Normotensive & 33 & 57.9 & 18 & 54.5 & & \\
\hline Diabetic & 20 & 35.1 & 13 & 39.4 & \multirow{2}{*}{0.167} & \multirow{2}{*}{0.683} \\
\hline Nondiabetic & 37 & 65.9 & 20 & 60.6 & & \\
\hline Smokers & 39 & 68.4 & 22 & 66.7 & \multirow{2}{*}{0.029} & \multirow{2}{*}{0.864} \\
\hline Nonsmokers & 18 & 31.6 & 11 & 33.3 & & \\
\hline
\end{tabular}

Baseline plasma BNP concentration was also associated with the dichotomous clinical outcome (good outcome and bad outcome) of study subjects. In group I ( $\mathrm{n}=57)$ good outcome and bad outcome found in $41(71.9 \%)$ and $16(28.1 \%)$ patients and those in group II $(\mathrm{n}=33)$ found in $6(18.2 \%)$ and $27(81.8 \%)$ patients respectively. Chi- square test was done to assess the association of baseline plasma BNP concentration with the clinical outcome of the study subjects. In group II patients having high baseline plasma BNP concentration significantly less good outcome but significantly high bad outcome found compared to those in group I patients having low plasma BNP concentration. (Table IV).

Table IV: Association of plasma BNP concentration with the clinical outcome (good and bad outcome) of the study subjects $(n=90)$.

\begin{tabular}{|c|c|c|c|c|c|c|}
\hline \multirow{2}{*}{ Group } & \multicolumn{2}{|c|}{$\begin{array}{c}\text { Good } \\
\text { outcome }\end{array}$} & \multicolumn{2}{c|}{$\begin{array}{c}\text { Bad } \\
\text { outcome }\end{array}$} & \multicolumn{1}{c|}{$\begin{array}{c}\mathbf{X}^{2} \\
\text { Value }\end{array}$} & $\begin{array}{c}\text { P } \\
\text { Value }\end{array}$ \\
\cline { 2 - 5 } & $(\mathbf{n})$ & $(\%)$ & $(\mathbf{n})$ & $(\%)$ & & \\
\hline $\begin{array}{c}\text { Group I } \\
(57)\end{array}$ & 41 & 71.9 & 16 & 28.1 & \multirow{2}{*}{24.199} & 0.000 \\
\hline $\begin{array}{c}\text { Group II } \\
(33)\end{array}$ & 6 & 18.2 & 27 & 81.8 & & \\
\hline
\end{tabular}


Table V shows the binary logistic regression analysis of plasma BNP concentration of study subjects with respect to good and bad outcome. Keeping the group I in reference category, it is found significant for group II (p- 0.000) with the odds ratio 11.5. The odds ratio of 11.5 indicates that there is 11.5 times higher chance of getting bad outcome in ACS subjects having higher plasma BNP concentration (group II) than those having low baseline plasma BNP concentration (group I) .

Table V: Logistic regression analysis of plasma BNP concentration with respect to clinical outcomes of study subjects

\begin{tabular}{|c|c|c|c|c|c|}
\hline Parameter & $\begin{array}{c}\text { Regression } \\
\text { Coefficient }\end{array}$ & $\begin{array}{c}\text { Standard } \\
\text { Error }\end{array}$ & P - Value & $\begin{array}{c}\text { Odds ratio } \\
\text { Exp (B) }\end{array}$ & $\begin{array}{c}\text { Regression } \\
\text { Coefficient }\end{array}$ \\
\hline $\begin{array}{c}\text { Group II } \\
\text { Outcom e }\end{array}$ & 2.4 & 0.5 & 0.000 & 11.5 & 2.4 \\
\hline $\begin{array}{c}\text { Group I } \\
\text { Outcom e }\end{array}$ & \multicolumn{3}{|c|}{ Reference Category } & 1 \\
\hline
\end{tabular}

- Mortality: Death of patients during study period as a consequence of acute coronary syndrome.

- Morbidity: Development of re-angina, re-infarction, arrhythmias, heart failure, cardiogenic shock and stroke during study period.

- Good outcome: Recovery after conservative treatment or after any intervention without developing complications like morbidity and mortality during study period.

- Bad outcome: After conservative treatment or any intervention, patient developed morbidity and mortality during study period.

\section{DISCUSSION}

In this prognostic cohort study, 90 diagnosed acute coronary syndrome (ACS) patients free from heart failure, renal disease, thyroid disorder and hepatic disorder were enrolled from the cardiology emergency department of BSMMU, NICVD and BIRDEM. Among 90 patients, 74 (82.2\%) patients were male and $16(17.8 \%)$ patients were female with the mean age of 51.8 years and age range of 30-90 years. Higher bad clinical outcomes in group II compared to group I indicates that the increasing baseline plasma BNP concentration is associated with worsening clinical outcome. In line with this study, many studies abroad have demonstrated BNP as a predictor of adverse outcome in ACS while others have refuted an association. This result was consistent with the several studies. Suzuki et al, (2004) found that the survival rate was significantly higher in patients with plasma BNP concentration $<180 \mathrm{pg} / \mathrm{ml}$ than those with plasma BNP concentration $>180 \mathrm{pg} / \mathrm{ml}$. Cox proportional hazard ratio analysis showed baseline plasma BNP as an independent predictor of death in ACS patients ${ }^{14}$. Kuklinska et al, in their study concluded that median plasma BNP value was higher in patients with adverse clinical outcomes $(\mathrm{p}<0.001)$. Patients with plasma BNP concentration $>99.2 \mathrm{pg} / \mathrm{ml}$ were significantly at higher risk of adverse clinical outcome. Logistic regression analysis showed that the plasma BNP concentration $>99.2 \mathrm{pg} / \mathrm{ml}$ was the strongest predictor of adverse outcome. ${ }^{15}$ Foody (2006) found that after adjustment of multiple risk factors, patients with plasma BNP level $>80 \mathrm{pg} / \mathrm{ml}$ had significantly greater risk for death when measured at baseline. ${ }^{16}$ In consistent with this findings $\mathrm{He} \mathrm{B}$ et al, (2006) in their study demonstrated the prognostic value of plasma BNP and C-reactive protein in patients with ACS undergoing percutaneous coronary intervention. They found that both plasma BNP and CRP were good predictors for early mortality and major adverse cardiac events but CRP had lost its predictive value after introduction of plasma BNP into the model, while BNP was still an independent predictor for mortality and major adverse cardiac events. ${ }^{17}$ Mega et al, (2004) in their study demonstrated that after adjustment of other clinical predictors including age, heart failure, HTN, heart rate, anterior MI, patients with baseline plasma BNP level $>80 \mathrm{pg} / \mathrm{ml}$ was associated with a seven-fold higher mortality risk (Odds ratio 7.2, $\mathrm{p}=0.001$ ). Patients with plasma BNP level $>80 \mathrm{pg} / \mathrm{ml}$ were also more likely to have impaired coronary flow $(\mathrm{p}=0.049) .{ }^{18}$ A study done by Ang et al, (2009) found that after adjustment of other predictors, baseline plasma BNP levels $>80 \mathrm{pg} / \mathrm{ml}$ was associated with subsequent cardiovascular events (Relative risk, 2.63, 95\% CI, 1.34-5.19). ${ }^{19}$ Sun, Wang and Zhang, (2006) demonstrated the plasma BNP as an important predictor of 
cardiac death in Chinese patients with ACS. In their study mean plasma BNP concentration in the non-survival group was significantly higher than that of the survival group. Multivariate logistic regression analysis incorporating age, sex, HTN, DM, left ventricular ejection fraction, Troponin-I and therapeutic regimens indicated that plasma BNP was an independent predictor of cardiac death in Chinese patients with odds ratio of 21.19. ${ }^{20}$

Through binary logistic regression analysis of plasma BNP concentration with respect to their good and bad clinical outcome keeping the group I in reference category, presentstudy have shown the odds ratio 11.5 for group II ( $\mathrm{p}-0.000)$ indicating 11.5 times higher chance of getting bad outcome in ACS subjects in group II having higher plasma BNP concentration than those in group I having low plasma BNP concentration. This result was consistent with several other studies. ${ }^{7,21,22}$ In a study Morrow et al (2005) demonstrated that after adjustment of other clinical predictors like age, sex, renal function, hypertension, diabetes and prior heart failure; a baseline plasma BNP $>80 \mathrm{pg} / \mathrm{ml}$ was associated with a 2 -fold higher long term risk of death (Adjusted hazard ratio 2.1). ${ }^{7}$ De Lemos et al, (2001) stated that the association of plasma BNP with clinical outcome remained significant in subgroups of patients who had STEMI, NSTEMI. ${ }^{21}$ In another study Morrow, de Lemos and Sabatine, (2003) showed that an elevated plasma BNP level $>80 \mathrm{pg} / \mathrm{ml}$ at presentation identifies patients with non ST elevation ACS who are at five-fold risk of developing new congestive heart failure or death $(\mathrm{p}<0.0001)$ independent of other clinical predictors. ${ }^{22}$ It can be concluded from this study that higher baseline plasma BNP concentration is associated with more adverse clinical outcomes in ACS patients. Since the baseline plasma BNP concentration at the onset of event shows incremental prognostic value, so plasma BNP can be used clinically as a biomarker of prognosis in ACS patients.

\section{REFERENCES}

1. Ross, R. Atherosclerosis: an inflammatory disease. N Eng J Med 1999; 340; 115-126.

2. Bhopal, R. What the risk of coronary heart disease in south Asian? A review of UK research.Journal of Public Health Medicine 2000; 22; 375-385.

3. Shah, PK. New insights in the pathogenesis and prevention of acute coronary syndromes. Am J Cardiol 1997; 79; 17-23.

4. Puelo, PR, Meyer, D, Wathen, C et al. Use of a rapid assay of sub forms of creatine kinase-MB to diagnose or rule out acute myocardial infarction.N Eng JMed 1994; 331; 561-566.
5. James, SK, Lindahl, B, Siegbahn, A et al. N-terminal pro brain natriuretic peptide and other risk markers for the separate prediction of mortality and subsequent myocardial infarction in patients with unstable coronary artery disease: a Global Utilization of Strategies To Open Occluded Arteries (GUSTO)-4 substudy.Circulation2003; 108; 275-281.

6. Yoshimura M, Yasue H, Okumura K et al. Different secretion patterns of atrial natriuretic peptide and brain natriuretic peptide in patients with congestive heart failure.Circulation 1993; 87; 464-469.

7. Morrow, DA, de Lemos, JA, Blazing, MA et al. Prognostic value of serial B-type natriuretic peptide testing during follow-up of patients with unstable coronary artery disease.JAMA 2005;294; 2866-2871.

8. Motwani, JG, McAlpine, $\mathrm{H}$, Kennedy, $\mathrm{N}$ et al. Plasma brain natriuretic peptide as an indicator for angiotensin converting enzyme inhibitor after myocardial infarction. Lancet 1993; 341; 1109-1113.

9. Jernberg, T, Stridsberg, M, Venge, P et al. N-terminal pro brain natriuretic peptide on admission for risk stratification of patients with chest pain and no ST- segment elevation. J Am Coll Cardiol 2002; 40; 437-445.

10. Talwar, S, Squire, IB, Downie, PF et al. Profile of Plasma N-terminal pro BNP following acute myocardial infarction. Correlation with left ventricular systolic dysfunction. Eur Heart J 2000; 21; 1514-1521.

11. De Lemos, JA and Morrow, DA. Brain natriuretic peptide measurement in acute coronary syndromes. Circulation 2002; 106; 2868-2870.

12. De Lemos, JA, McGuire, DK and Drazner, MH. B-type natriuretic peptide in cardiovascular disease. Lancet 2003; 362; 316-322.

13. Levin ER, Gardner DG and Samson YK. Natriuretic peptides. N Eng J Med 1998; 339; 321-328.

14. Suzuki, S, Yoshimura, M, Nakayama, M et al. Plasma level of B-type natriuretic peptide as a prognostic marker after acute myocardial infarction.Circulation 2004; 110; 1387-1391.

15. Kuklinska, AM, Sobkowtoz, B, Mrokzko, B et al. Prognostic significance of the admission plasma B-type natriuretic peptide measurement in patients with first ST-elevation myocardial infarction in comparison with C-reactive protein and TIMI risk score. Clinica Chemica Acta2007; 382; 106-111.

16. Foody, JM. BNP has prognostic value after ACS. Retrieved December, 2009 fromhttp:// cardiology.jwatch.org/cgi/content/full/ 2006/126/4

17. He, B, Ding, S, Pu, J et al. Prognostic value of plasma brain natriuretic peptide and $\mathrm{C}$ - reactive protein in patients with acute coronary syndromes underwent percutaneous 
coronary intervention. Zhonghua Xin Xue Guan Bing ZaZhi 2006; 34; 349-352.

18. Mega, JI, Morrow, DA, de Lemos JA et al. B-type natriuretic peptide at presentation and prognosis in patients with elevation myocardial infarction. J Am Coll Cardiol 2004; 44; 335-339.

19. Ang, SC, Kong, FG, Kao PC et al. Serial bedside B-type natriuretic peptide strongly predicts prognosis in acute coronary syndrome independent of echocardiographic abnormalities. Am Heart Journals 2009; 158; 133-150.

20. Sun, T, Wang, L and Zhang Y. Prognostic value of B-type natriuretic peptide in patients with acute coronary syndromes. Arch Med Res 2006; 37; 502-505.

21. DeLemos, JA, Morrow, DA, Bentley, JH et al. The prognostic value of B-type natriuretic peptide in patients with acute coronary syndromes. N Eng J Med 2001; 345; 1014-1021.

22. Morrow, DA, de Lemos, JA, and Sabatine, MS. Evaluation of B-type natriuretic peptide for risk assessment in unstable angina/non-ST-elevation myocardial infarction: B-type natriuretic peptide and prognosis in TACTICS-TIMI J Am Coll Cardiol 2003; 41; 1264-1272. 